\title{
Visual object categorization in the brain: what can we really learn from ERP peaks?
}

\author{
Guillaume A. Rousselet ${ }^{1}$, Cyril R. Pernet ${ }^{2}$, Roberto Caldara ${ }^{3}$ and Philippe G. Schyns ${ }^{1}$ \\ Centre for Cognitive Neuroimaging, Institute of Neuroscience and Psychology, University of Glasgow, Glasgow, UK \\ 2 Brain Research Imaging Centre, SINAPSE Collaboration, University of Edinburgh, Edinburgh, UK \\ ${ }^{3}$ Department of Psychology, University of Fribourg, Fribourg, Switzerland \\ *Correspondence: guillaume.rousselet@glasgow.ac.uk
}

\section{A commentary on}

Face-sensitive processes one hundred milliseconds after picture onset

by Dering, B., Martin, C. D., Moro, S., Pegna, A. J., and Thierry, G. (2011). Front. Hum. Neurosci. 5:93. doi: 10.3389/ fnhum.2011.00093

In three experiments, Dering et al. (2011) measured the amplitude and latency of the mean $\mathrm{P} 1$ and $\mathrm{N} 170$ in response to faces, cars, and butterflies, cropped or morphed. The N170 was sensitive to cropping but did not differentiate frontal views of faces and cars. Throughout, P1 amplitude was larger for faces than objects. The authors concluded that $\mathrm{P} 1$, not $\mathrm{N} 170$, is a reliable face-sensitive event.

Although Dering et al. (2011) and Thierry et al. (2007) correctly identified problems with P1 and N170 ERP interpretations, these same problems are evident in their own research, and, consequently, their results are equally inconclusive. We identify four shortcomings in Dering et al.'s approach that also apply to the literature they contest (e.g., Eimer, 1998; Allison et al., 1999; Carmel and Bentin, 2002; Itier and Taylor, 2004; Rousselet et al., 2004; Rossion and Jacques, 2008): categorical design, uncontrolled task demands, group statistics, and peak measurements. ERPs are worthwhile measurements of visual processing, but only when the shortcomings reviewed below are addressed.

\section{BEYOND CATEGORICAL DESIGNS}

Categorical designs compare few categories of input stimuli against brain measurements. When dealing with complex visual stimuli, categorical designs make it difficult to attribute a brain response to specific object categories (e.g., a face), features (e.g., the eye) or functions, because the specificity of the response (e.g., to the face) is deter- mined by contrast with responses from other categories (e.g., cars) and informal hypotheses tested. Unfortunately, category members share a dense correlative structure of low-level visual properties (e.g., luminance energy, main directions of orientation, spatial frequency composition), which cannot all be controlled with a finite number of contrast categories. Consequently, the brain response's specificity might be due to differences in input statistics, not to the category itself (Schyns et al., 2003).

Whereas Dering et al. (2011) controlled total luminance, contrast, and size, other physical dimensions affecting P1 amplitudes and categorical judgments were not controlled (e.g., spectral profiles of contrasted categories: VanRullen and Thorpe, 2001; Sowden and Schyns, 2006; VanRullen, 2006; Honey et al., 2008; Rousselet et al., 2008a). Consequently, a significant ERP peak difference between two input categories does not ensure that the difference relates to the category per se, as opposed to the uncontrolled statistics of low-level image properties (Schyns et al., 2003; Pernet et al., 2007). Categorical designs typically use few categories, but must still control for a much larger set of low-level image dimensions. By neglecting these experimental controls, it is almost inevitable that such designs will deliver the type of inconclusive results that animate unnecessary debates in the $\mathrm{P} 1$ and N170 face literature. Thierry et al.'s (2007) own results elegantly demonstrate this point. In their Experiment 3, they overlaid faces with cars and instructed observers to attend to either category. Here, when the two categories were better controlled for their low-level properties (though still not perfectly), the categorical modulations on the P1 component were abolished. Thus, varying levels of quality of stimulus control in Thierry et al.'s work fuels their own debate: if Dering et al. had correctly identified the
P1 face-sensitiveness, Thierry et al.'s (2007) third experiment would demonstrate an increased P1 amplitude for faces overlaid with cars. It did not. This contradiction illustrates the pitfalls of poor stimulus control.

\section{CONTROL OF TASK DEMANDS}

Dering et al.'s (2011) participants discriminated between faces and cars or butterflies. Assuming that the stimuli were properly controlled, observers in Dering et al.'s task could still discriminate a face from any car or butterfly using only the presence or absence of one of many face features (global appearance, texture, left or right eye, eyelashes, nose) or their combinations. This weakness highlights the broader (and often neglected) role of task demands in cognitive neuroimaging studies of recognition. A face can be categorized as "John," a Western Caucasian, who is 40, is handsome, in good health and currently has a happy face. Suggestion that "the P1 (or the N170) is categorically sensitive to faces as opposed to cars or butterflies" leaves unresolved the issue of whether the N170 is sensitive to the face, as an object category, or to the categorization task that is used to test the face with. If the P1 effects of Dering et al. arose from processing categorization-specific facial information, changing task demands (by changing the categorization performed on the same face) should differentially influence the brain response (Schyns, 1998; Pernet et al., 2007). The task demands of Dering et al. are not sufficiently controlled to inform the underlying information processing function of the P1 or N170.

\section{PROBLEMS WITH GROUP STATISTICS}

One of the main results of Dering et al. (2011) is that the N170 peak amplitudes do not differ between different stimulus categories. This result is only valid if the data conform to the assumptions of normality 
and heteroscedasticity that underlie the analyses. Standard linear statistics are extremely sensitive to departure from these assumptions leading to low statistical power (Wilcox, 2005). A convincing demonstration that the N170 is not a marker of face processing would require detailed investigation of the data distribution using robust statistics and actually showing the data. Moreover, effects present in individual observers might be washed out by grand average group statistics (Rousselet and Pernet, 2011; Rousselet et al., 2011). Effects might also be distributed across electrodes, as multivariate multi-electrode analyses can reveal (Philiastides and Sajda, 2006; Philiastides et al., 2006; Ratcliff et al., 2009). Without systematic univariate or multivariate analyses in single-subjects, null effects as reported for the N170 by Dering et al. are inconclusive.

Compared to group analyses, singletrial parametric analyses also provide more powerful tools to infer function because they exploit the richness of singletrial data to examine how parametrically manipulated input information co-varies with brain response variability (Hubel and Wiesel, 1979; Freedman et al., 2002, 2003; Ratcliff et al., 2009; Schyns et al., 2009a; Schyns, 2010; Pernet et al., 2011b; Rousselet and Pernet, 2011). In contradiction to Dering et al. (2011), such analyses have revealed sensitivity to categorical differences from about $100 \mathrm{~ms}$ to about $300 \mathrm{~ms}$, encompassing the N170 (Philiastides and Sajda, 2006; Philiastides et al., 2006; Rousselet et al., 2008b, 2011; Schyns et al., 2009b; van Rijsbergen and Schyns, 2009). Critically, parametric studies demonstrate that mean ERPs cannot elucidate the information content of single-trial fluctuations around the central tendency of the distribution (see Smith et al., 2004, Figure 1, for a graphical demonstration).

\section{EXTENDING FROM PEAK MEASUREMENTS}

Finally, by restricting analyses to peak ERP differences between groups, Dering et al.'s (2011) results fall short of providing a complete picture of the relevant brain responses. Important effects occur between peaks, which are quantifiable by applying analyses at all time points and electrodes (Delorme et al., 2007; Schyns et al., 2007, 2009b, 2011;
Rousselet et al., 2008b; Vizioli et al., 2010a,b; Pernet et al., 2011a). Peaks can index the end of a process rather than the specific information processing mechanism leading to this endpoint (Schyns et al., 2007).

In sum, Dering et al. (2011) applied a pervasive but now arguably out-dated approach to an otherwise useful brain measurement. The limitations of their approach apply as equally to their own results as to those they criticize. The issue of "face specificity" of the N170 should be addressed with more powerful methods such as using parametric manipulations of well-controlled stimuli, addressing task demands, and systematic single-subject statistics. Otherwise, numerous inconclusive data will continue to fuel unnecessary and opinionated controversies.

\section{REFERENCES}

Allison, T., Puce, A., Spencer, D. D., and McCarthy, G. (1999). Electrophysiological studies of human face perception. I: potentials generated in occipitotemporal cortex by face and non-face stimuli. Cereb. Cortex 9, 415-430.

Carmel, D., and Bentin, S. (2002). Domain specificity versus expertise: factors influencing distinct processing of faces. Cognition 83, 1-29.

Delorme, A., Westerfield, M., and Makeig, S. (2007). Medial prefrontal theta bursts precede rapid motor responses during visual selective attention. J. Neurosci. 27, 11949-11959.

Dering, B., Martin, C. D., Moro, S., Pegna, A. J., and Thierry, G. (2011). Face-sensitive processes one hundred milliseconds after picture onset. Front. Hum. Neurosci. 5:93. doi: 10.3389/fnhum.2011.00093

Eimer, M. (1998). Does the face-specific N170 component reflect the activity of a specialized eye processor? Neuroreport 9, 2945-2948.

Freedman, D. J., Riesenhuber, M., Poggio, T., and Miller, E. K. (2002). Visual categorization and the primate prefrontal cortex: neurophysiology and behavior. J. Neurophysiol. 88, 929-941.

Freedman, D. J., Riesenhuber, M., Poggio, T., and Miller, E. K. (2003). A comparison of primate prefrontal and inferior temporal cortices during visual categorization. J. Neurosci. 23, 5235-5246.

Honey, C., Kirchner, H., and VanRullen, R. (2008). Faces in the cloud: Fourier power spectrum biases ultrarapid face detection. J. Vis. 8, 1-13.

Hubel, D. H., and Wiesel, T. N. (1979). Brain mechanisms of vision. Sci. Am. 241, 150-162.

Itier, R. J., and Taylor, M. J. (2004). N170 or N1? Spatiotemporal differences between object and face processing using ERPs. Cereb. Cortex 14, 132-142.

Pernet, C., Schyns, P. G., and Demonet, J. F. (2007). Specific, selective or preferential: comments on category specificity in neuroimaging. Neuroimage 35, 991-997.

Pernet, C. R., Chauveau, N., Gaspar, C., and Rousselet, G. A. (2011a). LIMO EEG: a toolbox for hierarchical Linear Modeling of EletroEncephaloGraphic data. Comput. Intell. Neurosci. doi: 10.1155/2011/831409
Pernet, C. R., Sajda, P., and Rousselet, G. A. (2011b). Single-trial analyses: why bother? Front. Psychol.2:322. doi: 10.3389/fpsyg.2011.00322

Philiastides, M. G., Ratcliff, R., and Sajda, P. (2006). Neural representation of task difficulty and decision making during perceptual categorization: a timing diagram. J. Neurosci. 26, 8965-8975.

Philiastides, M. G., and Sajda, P. (2006). Temporal characterization of the neural correlates of perceptual decision making in the human brain. Cereb. Cortex 16, 509-518.

Ratcliff, R., Philiastides, M. G., and Sajda, P. (2009). Quality of evidence for perceptual decision making is indexed by trial-to-trial variability of the EEG. Proc. Natl. Acad. Sci. U.S.A. 106, 6539-6544.

Rossion, B., and Jacques, C. (2008). Does physical interstimulus variance account for early electrophysiological face sensitive responses in the human brain? Ten lessons on the N170. Neuroimage 39, 1959-1979.

Rousselet, G.A., Gaspar, C.M., Wieczorek, K. P., and Pernet, C.R. (2011). Modeling single-trial ERP reveals modulation of bottom-up face visual processing by top-down task constraints (in some subjects). Front. Psychol. 2:137. doi: 10.3389/fpsyg.2011.00137

Rousselet, G. A., Husk, J. S., Bennett, P. J., and Sekuler, A. B. (2008a). Time course and robustness of ERP object and face differences. J. Vis. 8, 1-18.

Rousselet, G. A., Pernet, C. R., Bennett, P. J., and Sekuler, A. B. (2008b). Parametric study of EEG sensitivity to phase noise during face processing. BMC Neurosci. 9 , 98. doi: 10.1186/1471-2202-9-98

Rousselet, G. A., Macé, M. J., and Fabre-Thorpe, M. (2004). Animal and human faces in natural scenes: how specific to human faces is the N170 ERP component? J. Vis. 4, 13-21.

Rousselet, G.A., and Pernet, C. R. (2011). Quantifying the time course of visual object processing using ERPs: it's time to up the game. Front. Psychol. 2:107. doi: 10.3389/fpsyg.2011.00107

Schyns, P. G. (1998). Diagnostic recognition: task constraints, object information, and their interactions. Cognition 67, 147-179.

Schyns, P. G. (2010). Grand challenges in perception science: modeling the future. Front. Psychol. 1:10. doi: 10.3389/fpsyg.2010.00010

Schyns, P. G., Gosselin, F., and Smith, M. L. (2009a) Information processing algorithms in the brain. Trends Cogn. Sci. (Regul. Ed.) 13, 20-26.

Schyns, P. G., Petro, L. S., and Smith, M. L. (2009b). Transmission of facial expressions of emotion coevolved with their efficient decoding in the brain: behavioral and brain evidence. PLoS ONE 4, e5625. doi: 10.1371/journal.pone.0005625

Schyns, P. G., Jentzsch, I., Johnson, M., Schweinberger, S. R., and Gosselin, F. (2003). A principled method for determining the functionality of brain responses. Neuroreport 14, 1665-1669.

Schyns, P. G., Petro, L. S., and Smith, M. L. (2007). Dynamics of visual information integration in the brain for categorizing facial expressions. Curr. Biol. 17, 1580-1585.

Schyns, P. G., Thut, G., and Gross, J. (2011). Cracking the code of oscillatory activity. PLoS Biol. 9, e1001064. doi: 10.1371/journal.pbio.1001064

Smith, M. L., Gosselin, F., and Schyns, P. G. (2004). Receptive fields for flexible face categorizations. Psychol. Sci. 15, 753-761.

Sowden, P. T., and Schyns, P. G. (2006). Channel surfing in the visual brain. Trends Cogn. Sci. (Regul. Ed.) 10, 538-545. 
Thierry, G., Martin, C. D., Downing, P., and Pegna, A. J. (2007). Controlling for interstimulus perceptual variance abolishes N170 face selectivity. Nat. Neurosci. 10, 505-511.

van Rijsbergen, N. J., and Schyns, P. G. (2009). Dynamics of trimming the content of face representations for categorization in the brain. PLoS Comput. Biol. 5, e1000561. doi: 10.1371/journal. pcbi.1000561

VanRullen, R. (2006). On second glance: still no high-level pop-out effect for faces. Vision Res. 46, 3017-3027; author reply 3028-3035.
VanRullen, R., and Thorpe, S. J. (2001). The time course of visual processing: from early perception to decisionmaking. J. Cogn. Neurosci. 13, 454-461.

Vizioli, L., Foreman, K., Rousselet, G. A., and Caldara, R. (2010a). Inverting faces elicits sensitivity to race on the N170 component: a cross-cultural study. J. Vis. 10,11-23.

Vizioli,L., Rousselet, G.A., and Caldara, R. (2010b). Neural repetition suppression to identity is abolished by otherrace faces. Proc. Natl. Acad. Sci. U.S.A. 107,20081-20086.

Wilcox, R. R. (2005). Introduction to Robust Estimation and Hypothesis Testing, 2nd Edn. New York, NY: Elsevier Academic Press.
Received: 17 October 2011; accepted: 14 November 2011; published online: 01 December 2011.

Citation: Rousselet GA, Pernet CR, Caldara R and Schyns $P G$ (2011) Visual object categorization in the brain: what can we really learn from ERP peaks? Front. Hum. Neurosci. 5:156. doi: 10.3389/fnhum.2011.00156

Copyright (C) 2011 Rousselet, Pernet, Caldara and Schyns. This is an open-access article distributed under the terms of the Creative Commons Attribution Non Commercial License, which permits non-commercial use, distribution, and reproduction in other forums, provided the original authors and source are credited. 